\title{
Intraoperative plateau pressure measurement using modern anesthesia machine ventilators
}

\author{
Mohammad A. Helwani, MD • Nahel N. Saied, MBBCh
}

Received: 14 November 2012/ Accepted: 20 December 2012/Published online: 3 January 2013

(C) Canadian Anesthesiologists' Society 2012

\section{To the Editor,}

Monitoring respiratory system mechanics is vital to guide safe and effective ventilator management. Transalveolar pressure (tAp) is the driving force of alveolar distension, which allows for effective respiration; however, overdistension may lead to inflammation and subsequent destruction of alveoli. Unfortunately, there is no practical way to measure tAp directly; hence, surrogate measures are often used. Peak airway pressure (PAP), commonly monitored in patients undergoing general anesthesia, consists of static and dynamic components. Volume-preset ventilation allows determination of the respiratory system mechanics. In a muscle-relaxed patient, PAP consists of two components, i.e., the dynamic pressure to drive gas across the resistance (Pres) of the bronchial tree and the static pressure to expand the alveoli against the elastic recoil of the lungs and chest wall (Plateau pressure, [Pplat]), which is more reflective of tAp than PAP. ${ }^{1}$ Plateau pressure can be displayed easily on the new generation of anesthesia machine ventilators by inserting an end-inspiratory pause of $0.5-1 \mathrm{sec}^{2}$ Calculating the difference in airway pressure during flow and no-flow states allows the calculation of airway resistance (Pres $=$ PAP - Pplat).

Diagnostic and therapeutic information can be extracted by distinguishing components of PAP. This information can help

M. A. Helwani, MD ( $\square)$

Washington University School of Medicine, St. Louis, MO, USA

e-mail: helwanim@anest.wustl.edu

\section{N. N. Saied, MBBCh}

Vanderbilt University School of Medicine, Nashville, TN, USA the anesthesia provider to narrow the differential diagnosis of high PAP to help solve oxygenation/ventilation issues and tailor treatment. ${ }^{3}$ For example, elevated Pres at constant flow may indicate bronchospasm or endotracheal tube obstruction (Figure). Conversely, falling Pres may correspond with a response to bronchodilators. Elevated Pplat indicates excessive tidal volume or decreased lung and/or chest wall compliance (e.g., pulmonary edema, acute lung injury, or abdominal distension). ${ }^{1}$

Positive pressure ventilation may cause or exacerbate lung injury due to an increase in lung stretching which is best assessed by the transpulmonary pressure or the tAp. Separation of lungs from chest wall compliance requires an esophageal pressure measurement to approximate pleural pressure. ${ }^{3}$ Due to the technical and accuracy limitations, esophageal manometry is not widely used, and Pplat is used as a surrogate to guide titration of mechanical ventilation.

As a lung protective ventilation strategy, it is recommended that Pplat be maintained $\leq 30 \mathrm{~cm} \mathrm{H}_{2} \mathrm{O}$ to prevent alveolar overdistension and barotrauma, especially in acute lung injury and during one-lung ventilation. ${ }^{4,5}$ Whenever chest compliance is reduced, the stiff chest contributes substantially to Pplat. This should be taken into consideration when assessing lung stretch, as higher Pplat may still be safe due to the limitation of alveolar distension by the chest wall.

We present two examples of procedures to acquire Pplat in the operating room using two popular anesthesia machines. For the GE S/5 Aespire ${ }^{\circledR}$ SmartVent (General Electric Company, Madison, WI, USA) (Figure), select setup/calibration from the main menu (Figure, upper panel); then change the inspiratory pause from 0 to $30-60 \%$ to achieve a pause of $0.5-1 \mathrm{sec}$, and Pplat will be displayed (Figure, lower panel). With a respiratory rate of 8 breaths $\mathrm{min}^{-1}$ and inspiratory:expiratory (I:E) ratio $1: 2$, 
Figure Steps to display Pplat on the GE S/5 Aespire ${ }^{\circledR}$ SmartVent anesthesia machine. Upper panel: Select "Setup/ Calibration menu" from the main menu. Middle panel: Set the inspiratory pause to $30 \%$ of the inspiratory time (Ti). Lower panel: Pplat is displayed, and in this example, the Pplat $=22$ indicates a safe transpulmonay pressure. Pres $=$ PAP - Pplat $=$ $15 \mathrm{~cm} \mathrm{H}_{2} \mathrm{O}\left(>5-7 \mathrm{~cm} \mathrm{H}_{2} \mathrm{O}\right)$ indicating increased airway resistance

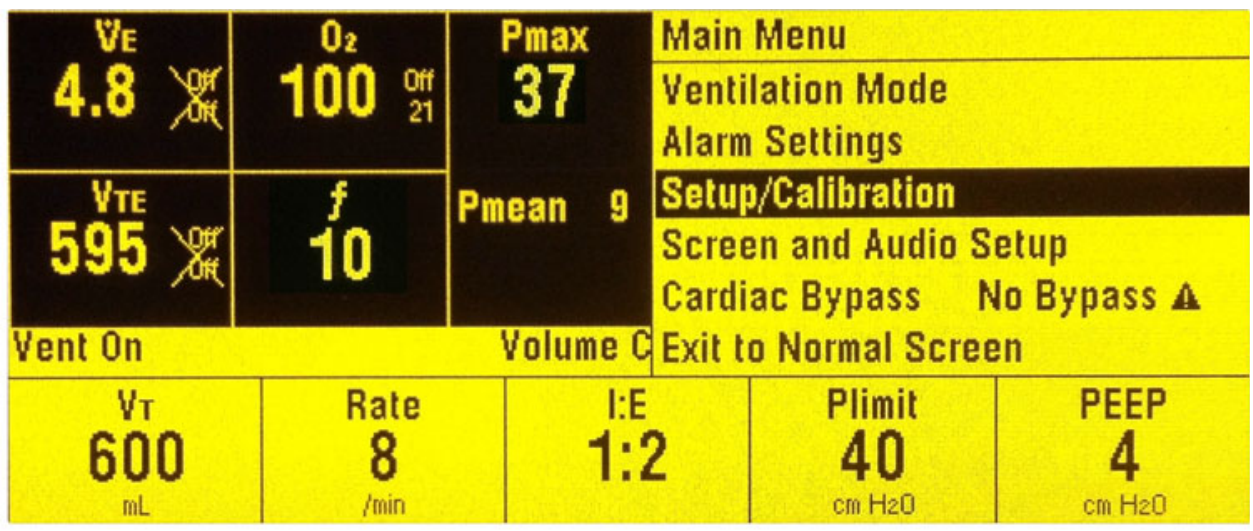

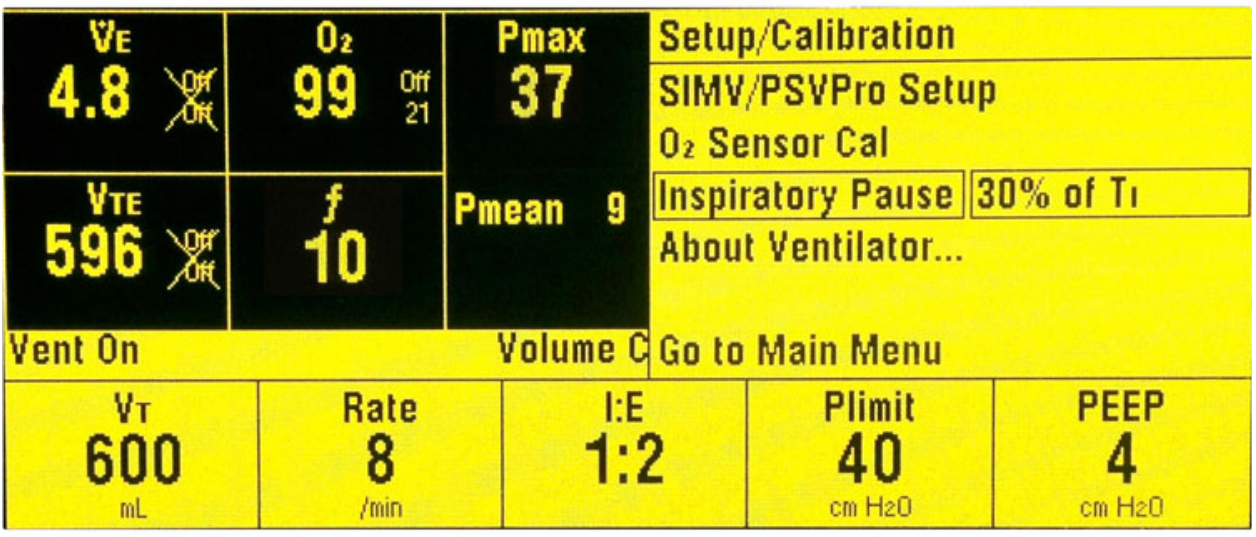

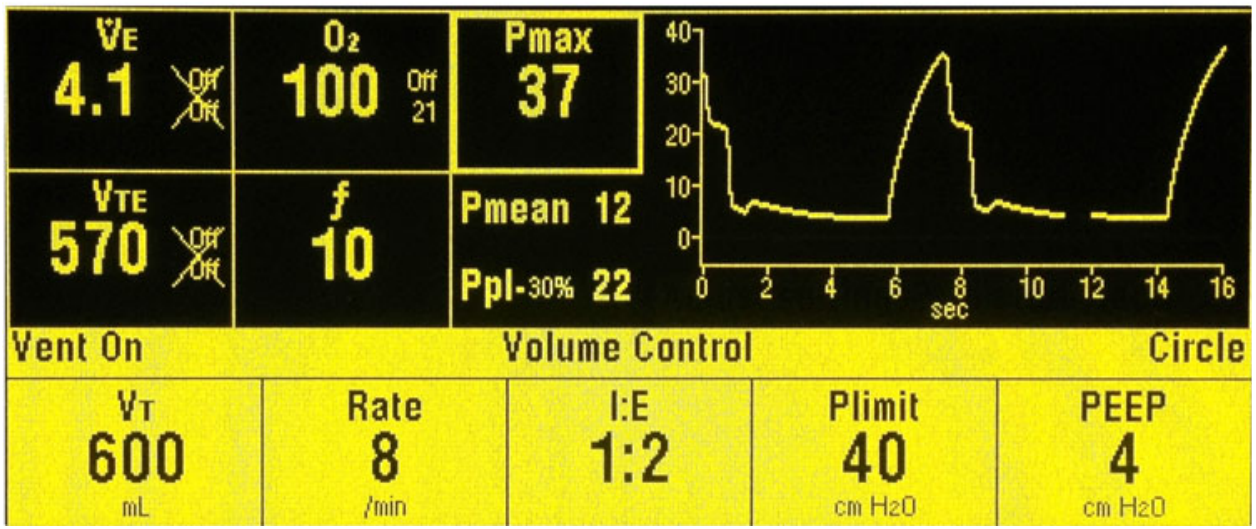

the inspiratory time for each breath $=2.5 \mathrm{sec}$ and a $30 \%$ pause $=0.8 \mathrm{sec}$ (Figure, middle panel). To obtain Pplat using a Dräger Apollo ${ }^{\circledR}$ anesthesia machine (Dräger Medical Inc., Telford, PA, USA), select extra settings from the main screen; then change the inspiratory pause from 0 to $30-60 \%$.

To have Pplat displayed at all times, biomedical engineers can set the inspiratory pause as default settings. While this may mildly increase the PAP, it may decrease dead space ventilation and improve $\mathrm{CO}_{2}$ elimination. ${ }^{6}$ In conclusion, understanding respiratory system mechanics is critical. Separation of PAP components can be achieved in the operating room by inserting an end-inspiratory pause.
This maneuver may glean important information to guide mechanical ventilation under general anesthesia.

Competing interests None declared.

\section{References}

1. Schmidt GA. Chapter 32. Ventilator waveforms: clinical interpretation. In: Hall JB, Schmidt GA, Wood LD (Eds). Principles of Critical Care, 3rd ed. NY: McGraw-Hill; 2005: 427-43.

2. Leatherman $J W$. Mechanical ventilation in obstructive lung disease. Clin Chest Med 1996; 17: 577-90. 
3. Moon RE, Camporesi EM. Respiratory monitoring. In: Miller RD, editor. Anesthesia. 5th ed. NY: Churchill Livingstone Inc.; 2000. p. $1278-83$.

4. Boussarsar M, Thierry $G$, Jaber $S$, Roudot-Thoraval F, Lemaire F, Brochard $L$. Relationship between ventilatory settings and barotrauma in the acute respiratory distress syndrome. Intensive Care Med 2002; 28: 406-13.
5. Lytle FT, Brown DR. Appropriate ventilatory settings for thoracic surgery: intraoperative and postoperative. Semin Cardiothorac Vasc Anesth 2008; 12: 97-108.

6. Pillet $O$, Choukroun $M L$, Castaing $Y$. Effects of inspiratory flow rate alterations on gas exchange during mechanical ventilation in normal lungs. Efficiency of end-inspiratory pause. Chest 1993; 103: 1161-5. 